to the board of referees. The members of the board were Mr. E. F. M. Maxwell (lay member), Dr. A. Beauchamp, and Professor T. N. A. Jeffcoate.

Mr. J. M. Keidan appeared for the Minister and Miss Rose Heilbron, Q.C., for Dr. Dalton. The Medical Defence Union instructed Messrs. Hempsons, solicitors, to act for Dr. Dalton.

Mr. Keidan contended that the hormone preparations ethisterone, progesterone, and methyltestosterone were drugs more expensive than was reasonably necessary. Less expensive treatment would have sufficed. In the event there was no evidence about the methyltestosterone, and no specific argument about it was addressed to the board.

\section{Board's Conclusions}

After taking oral and written evidence the board found that ethisterone and progesterone were in the main prescribed for women suffering from the premenstrual syndrome. In ten cases progesterone was prescribed for women suffering from ailments during pregnancy as a prophylactic against toxaemia of childbirth.

The premenstrual syndrome is an established ailment said to affect $40 \%$ of women of child-bearing age, and hormone preparations are now an established remedy for it. The first important paper on the subject in England was published in 1953.* Before that the treatment was known in the United States. It is now well known to gynaecologists here; it is described in several textbooks, including some intended for undergraduate medical students, but is not yet well known to general practitioners. It does not remove the cause of the disease: it only controls the symptoms. It is therefore a continuing treatment. Each dose is expensive. Milder symptoms can equally well be controlled by less expensive remedies-diuretics, sedatives, and psychiatry. Consequently the prescription of hormone preparations can be justified only when the symptoms are very severe and other less expensive remedies have been tried without avail.

The board then eliminated various errors that had come into the comparison between Dr. Dalton's and the areal prescribing costs.

Dr. Dalton calculated that $8.5 \%$ of the women who came to her for treatment of these symptoms were ultimately given ethisterone or progesterone. She had on her list 1,400 women, of whom 850 would have been of child-bearing age. Of these the number who complained of symptoms indicative of premenstrual syndrome must have been 400 , or $47 \%$. It was to be expected that Dr. Dalton would attract to her practice not only more women than the average, but also that the proportion of those women complaining of these symptoms would be higher than the average.

Dr. Dalton, being concerned at the high cost of ethisterone and progesterone, adopted a special method for determining whether or not to prescribe them. She gave to each patient complaining of the symptoms a chart on which were to be recorded the symptoms for the next three months. During this period the patient was given the less expensive treatment consisting in fluid and salt restriction, diuretics, and sedatives. Ethisterone and progesterone were given only in the light of information about both the symptoms and the effect of other treatment over a period of three months.

Since the medicinal art is largely experimental, the efficacy of a remedy has some bearing on the reasonableness of its cost. Dr. R. Greene, one of the witnesses, found that progesterone was effective in $80 \%$ of the cases, ethisterone in only $40 \%$, but ethisterone or progesterone in $90 \%$. The medical members of the board were satisfied that the cost incurred in prescribing for these patients was reasonably necessary for their proper treatment.

The board then considered Dr. Dalton's claim to have discovered a connexion between premenstrual symptoms during pregnancy and subsequent toxaemia. An experiment based on her theory had been carried on with her cooperation at the City of London Maternity Hospital since June, 1955, and a graph was produced showing that this

*Greene, R., and Dalton, K., British Medical Journal, 1953, $1,1007$. experiment was followed by a sharp fall in the incidence of toxaemia at that hospital. Similar controlled trials were now being conducted at University College Hospital, London, but the results were not yet available. The board concluded that Dr. Dalton was entitled to use her discretion to prescribe a remedy which would not only relieve the symptoms but also avert the toxaemia of which, as she believed, they were a warning.

Mr. Keidan conceded that Dr. Dalton was neither extravagant nor reckless. But, he said, she diagnosed too many patients as suffering from premenstrual tension and was too ready to turn to progesterone. The board states that it drew the opposite inference from the evidence. Women who heard of progesterone treatment were no longer willing to submit to a disability which they formerly endured without complaint, and Dr. Dalton took great care in diagnosing their symptoms.

“Dr. Dalton's prescribing costs were three times as much as the average. It might appear that if all doctors followed her example the cost of the pharmaceutical services would be trebled, an increase of $1100 \mathrm{~m}$. a year. But we think, first, the figure for Dr. Dalton's costs in the table would require a very considerable adjustment before it could properly be compared with the average. Second, if progesterone does come into general use there is bound to be a big fall in its cost. There was indeed some evidence that this fall had already begun. Third, if effective but expensive remedies are discovered for common ailments it must be expected that the cost of the pharmaceutical services will go up.'

The board decided that the cost of the drugs and appliances ordered by Dr. Dalton in September, 1955, did not exceed what was reasonably necessary for the proper treatment of the persons concerned.

\section{INTERIM ADJUSTMENT OF REMUNERATION}

\section{REGULATIONS FOR 5\% INCREASE}

The Ministry of Health and Department of Health for Scotland have issued regulations implementing the promise of an interim adjustment in remuneration given by the Prime Minister in the House of Commons on April 16. Under these regulations, the remuneration of senior hospital medical staff has been increased by $5 \%$ from May 1 . The new rates per annum for whole-time appointments (with the old rates in brackets) are given below. Payment for part-time appointments is on a weighted pro rata basis.

Consultants: (1) appointed earlier than 31-starting salary $£ 1,890$ ( $£ 1,800)$; (2) appointed at 31 -starting salary $£ 2,04710$ s. $(£ 1,950)$; (3) appointed at 32 or over-starting salary $£ 2,205$ by $£ 131$ 5s. to $£ 3,255$ ( $£ 2,100$ by $£ 125$ to $£ 3,100$ ). The maximum salary with the addition of the maximum distinction award will now total $£ 5,455(£ 5,300)$.

Senior hospital medical officers: (1) appointed earlier than 31 $-£ 1,54815 \mathrm{~s}$. (£1,475); (2) appointed at $31-£ 1,6015 \mathrm{~s}$. (£1,525); (3) appointed at 32 or over- $-11.65315 \mathrm{~s}$. by $£ 5210 \mathrm{~s}$. to $£ 2,1265 \mathrm{~s}$. (£1,575 by $£ 50$ to $£ 2,025$ ).

\section{General Practitioners}

From May $15 \%$ has also been added to the aggregate net remuneration of general practitioners after the deduction of practice expenses. Special regulations are not required for this. The Ministry proposes that, as indicated by the Prime Minister, the best method of distributing the extra money should be the subject of consultations with representatives of the profession.

Corrections.-In paragraph 175 of the Annual Report of Council (Supplement, April 13, p. 161) Professor Constantine Choremis is erroneously described as Professor of Bacteriology. $\mathrm{He}$ is Professor of Paediatrics.

In the report of Mr. R. S. Murley's remarks at the dinner of the Fellowship for Freedom in Medicine (Supplement, April 27, p. 231) the sentence reading "Where they differed, however, was in their advocacy of a type of organization which .... would ... more closely associate financial operational responsibility ..." should have read " more closely associate financial with operational responsibility." 